\title{
Lip Shaving in Carcinoma Lower Lip and Reconstruction by Local Advancement Mucosal Flap Under Local Anesthesia: A Case Report
}

\author{
Tareq Mohammed ${ }^{1}$, Mamoon $\mathrm{TB}^{2}$, Md Sirajul Islam ${ }^{3}$, Md Aminul Islam $^{4}$, Farid Uddin Milki ${ }^{5}$, ASM Lutfur Rahman ${ }^{6}$, Nazmul \\ Hossain Chowdhury ${ }^{7}, *$ Md Ashraful Islam ${ }^{8}$ \\ ${ }^{1}$ Assistant Registrar ENT, Bangladesh Medical College Hospital \\ ${ }^{2}$ Assistant Registrar ENT, Bangladesh Medical College Hospital \\ ${ }^{3}$ Junior Consultant ENT, Bangladesh Medical College Hospital \\ ${ }^{4}$ Registrar ENT, Bangladesh Medical College Hospital \\ ${ }^{5}$ Consultant ENT, Bangladesh Medical College Hospital \\ ${ }^{6}$ Resident Surgeon, Bangladesh Medical College Hospital \\ ${ }^{7}$ Assistant Registrar ENT, Bangladesh Medical College Hospital \\ ${ }^{8}$ Professor and Head, Otolaryngology-Head \& Neck Surgery, Bangladesh Medical College Hospital
}

\begin{abstract}
The lips are one of the most important features of the face; and are functionally and aesthetically very important. It serves as border of the oral commissure, provides access to oral cavity and contributes to oral competence. It is important for verbal expression and fundamental for facial expression and overall appearance of face ${ }^{1}$. Excessive sun exposure and tobacco use, may develop cancer. The cancer can occur anywhere along the upper or lower lip, but is most common on the lower lip. Most lip cancers are squamous cell carcinomas. Surgery is the main stay of treatment and lip shave is an established modality for superficial lesion followed by reconstruction. Extensive surgery may be necessary for larger lesion. Careful planning and reconstruction can restore eating and speaking normally, and also achieve a satisfactory appearance after surgery. Evidence supports that the concept of lip reconstruction started as early as $1000 \mathrm{BC}$ in the sacred texts of great Susruta, India ${ }^{2}$. Lip mucosa is very special and it is recommended to reconstruct the surgical defect with lip tissue whenever possible, as any other tissue is never comparable or can replace the lip tissue $^{3}$. This is the example of this presented case.
\end{abstract}

Keywords:- Lip squamous cell carcinoma (SCC), lip shaving, reconstruction.

\section{INTRODUCTION}

The lips are complex and specialized structures and most mobile elements of lower part of face. It has aesthetic and functional role that cannot be replaced by other tissue of body. It is always better to replace the lip tissue with ones' own tissue whenever possible. Majority of lip defect occurs due to trauma or tumor excision. Basal cell carcinoma (BCC) is relatively common in upper lip and SCC is more common in sun exposed part of lower lip. Both are common in elderly people. Small defect should be primarily closed locally but the decision making relies on a defect occupying more than half. Superficial defect involving vermilion of lip can be closed by vermilion mucosa only, if necessary, some mucosa can be undermined or advanced to cover the defect without any obvious deformity ${ }^{3}$. In this case, we would like to describe repair of such a defect created after shaving of the lower lip for a lip lesion. Several flaps have been described throughout the literatures but here we have mentioned the simplest method by which one can close a defect in an effective acceptable way with oncological safety.

\section{CASE REPORT}

A 65 year old lady reported to otolaryngology outpatient department (OPD0 with the complaint of a swelling in left half of lower lip for 6 months duration. She noticed a small nodular swelling in her left half of lower lip 6 months ago which was gradually increasing. She had no local pain or burning sensation. According to the statement of the patient, she developed a small similar swelling in the lower lip 5 years back which had disappeared with local homeopathy treatment. Again she initially tried with the same homeopathy treatment for the present lesion with no improvement at all. On the contrary, the lesion started increasing in size with whitish discoloration of entire oral cavity including lower lip. There was alteration of taste and slight burning sensation in the oral cavity during taking meal. She was hypertensive but non diabetic. She used to take betel leaf with slacked lime and nuts regularly. The lady was house wife and did not give any history of prolonged sun exposure.

On local examination there was an ulceroprolipharative lesion in left half of lower lip measuring 2.5 $\times 1.5 \mathrm{~cm}$, non-tender, indurated with irregular cauliflower like surface. It did not bleed on touch. The lesion was $1 \mathrm{~cm}$ lateral to the angle of mouth and $0.5 \mathrm{~cm}$ distal to the vermillion border. On intraoral examination there was extensive leukoplakia involving inner aspect of lips, buccal mucosa, palatal mucosa and tongue. There was no palpable lymph nodes in the neck. (b) 


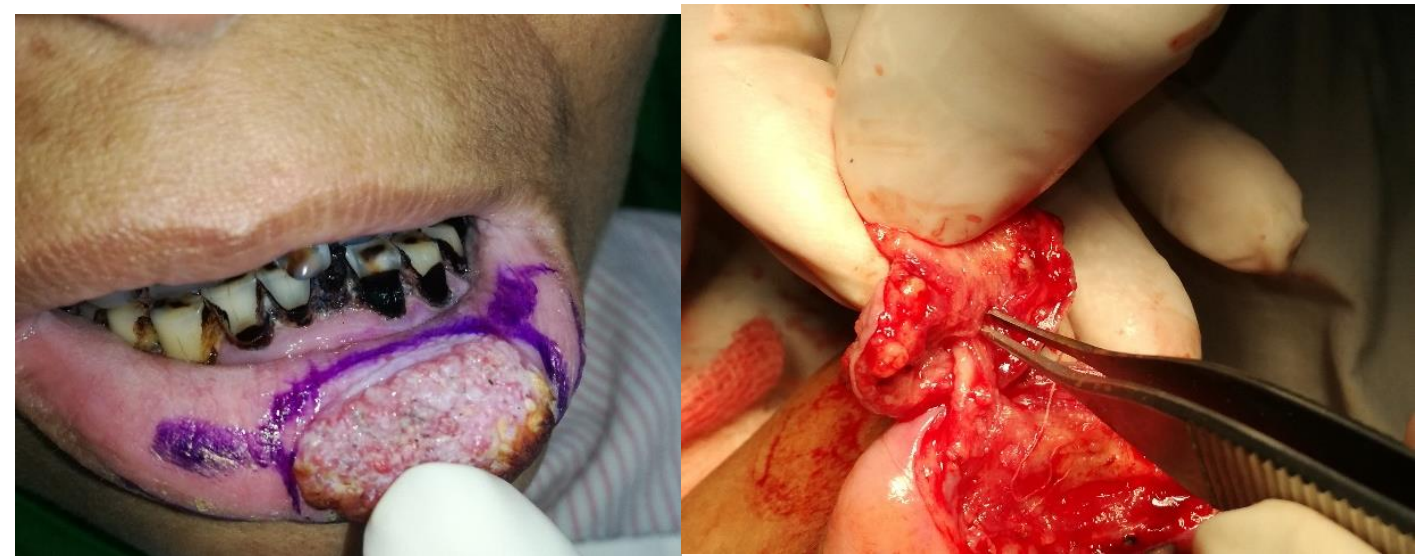

(a)

(b)

Fig 1:- (a) Primary lesion, (b) excision of the lesion

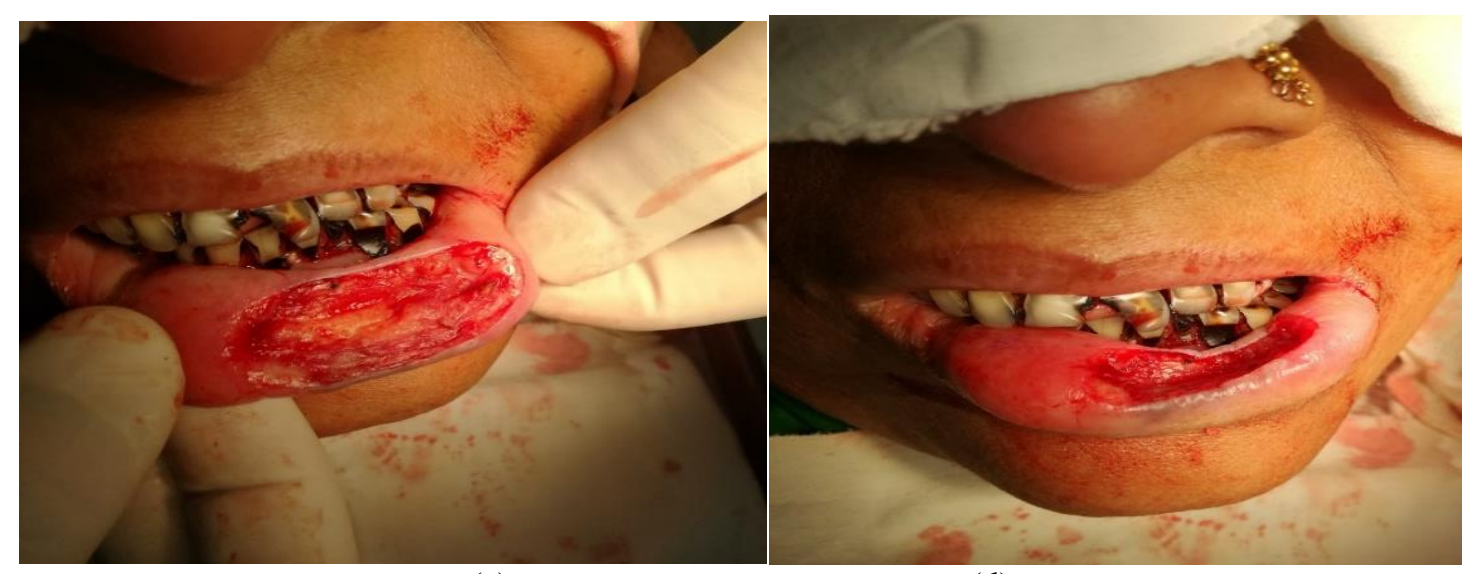

(c)

(d)

Fig 2:- (c-d) after excision

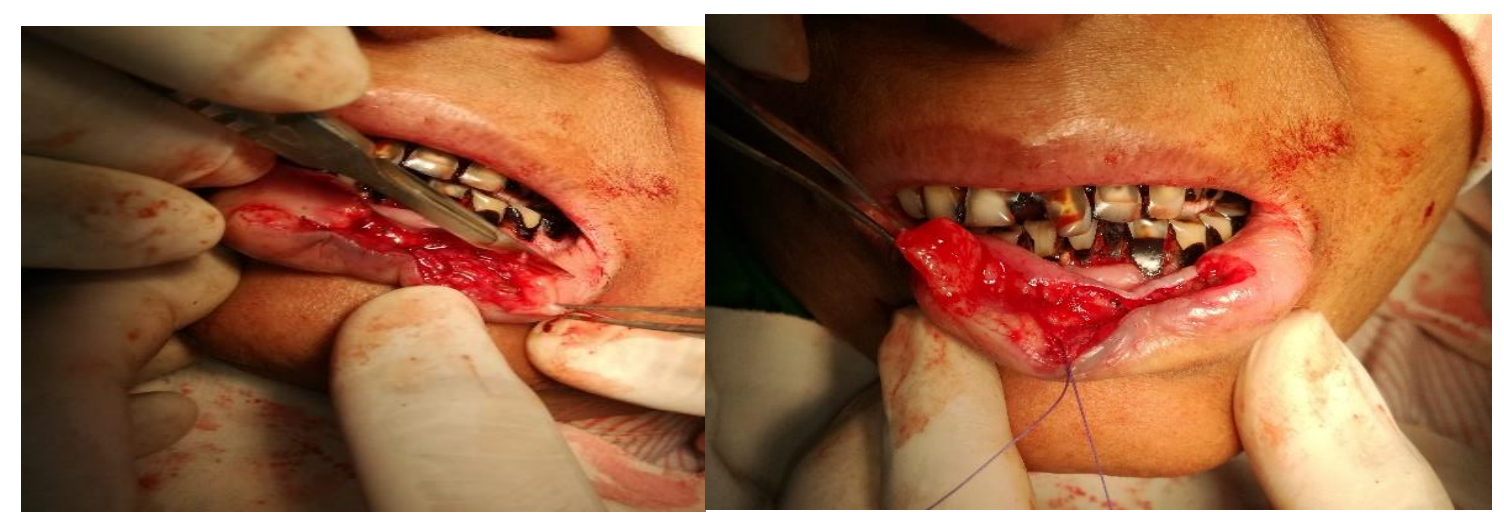

(e)

(f)

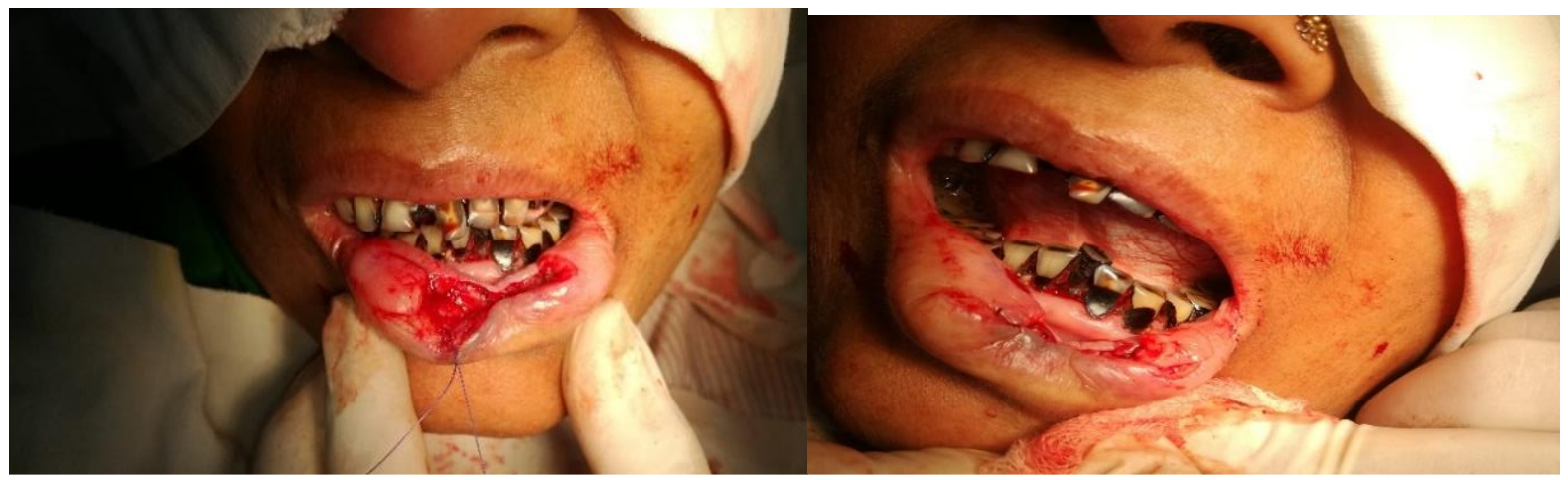

(g)

(h) 


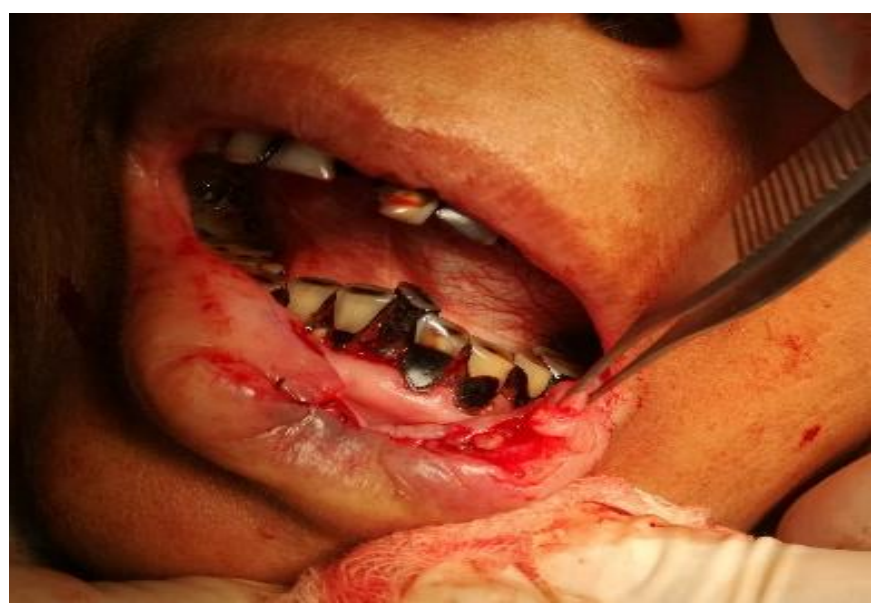

(i)

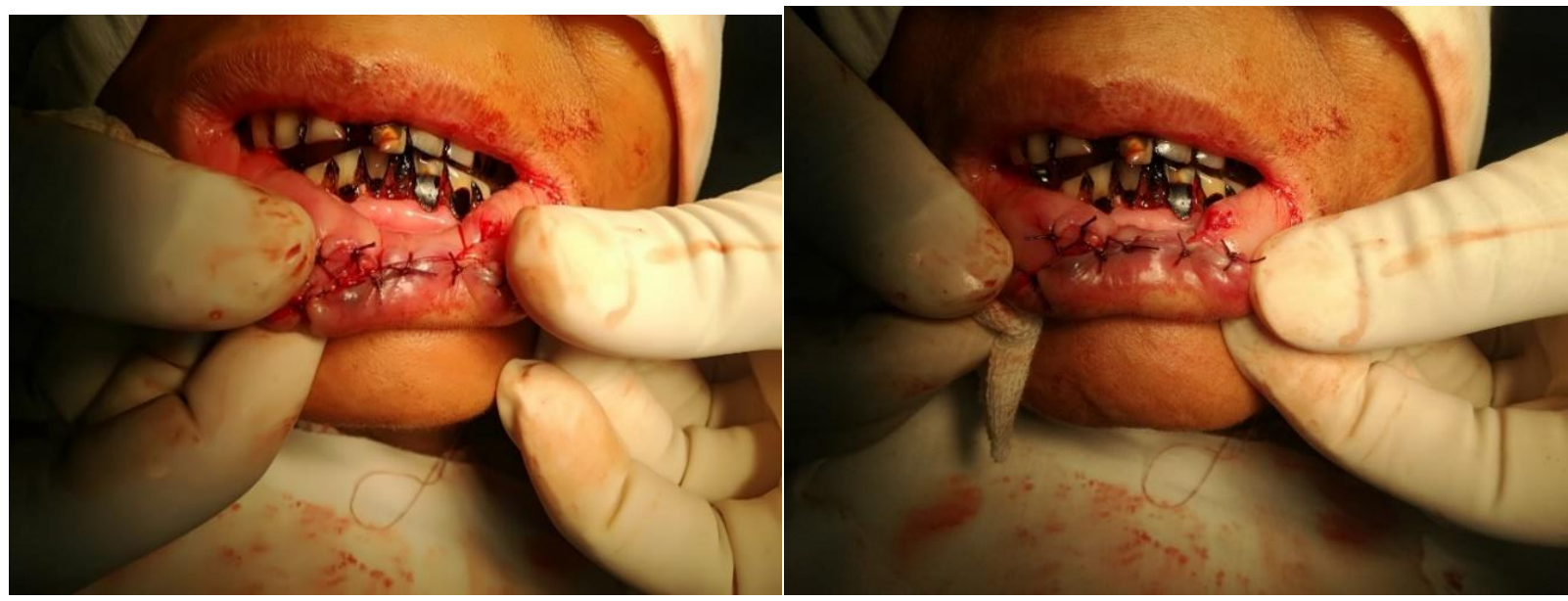

(m)

(n)

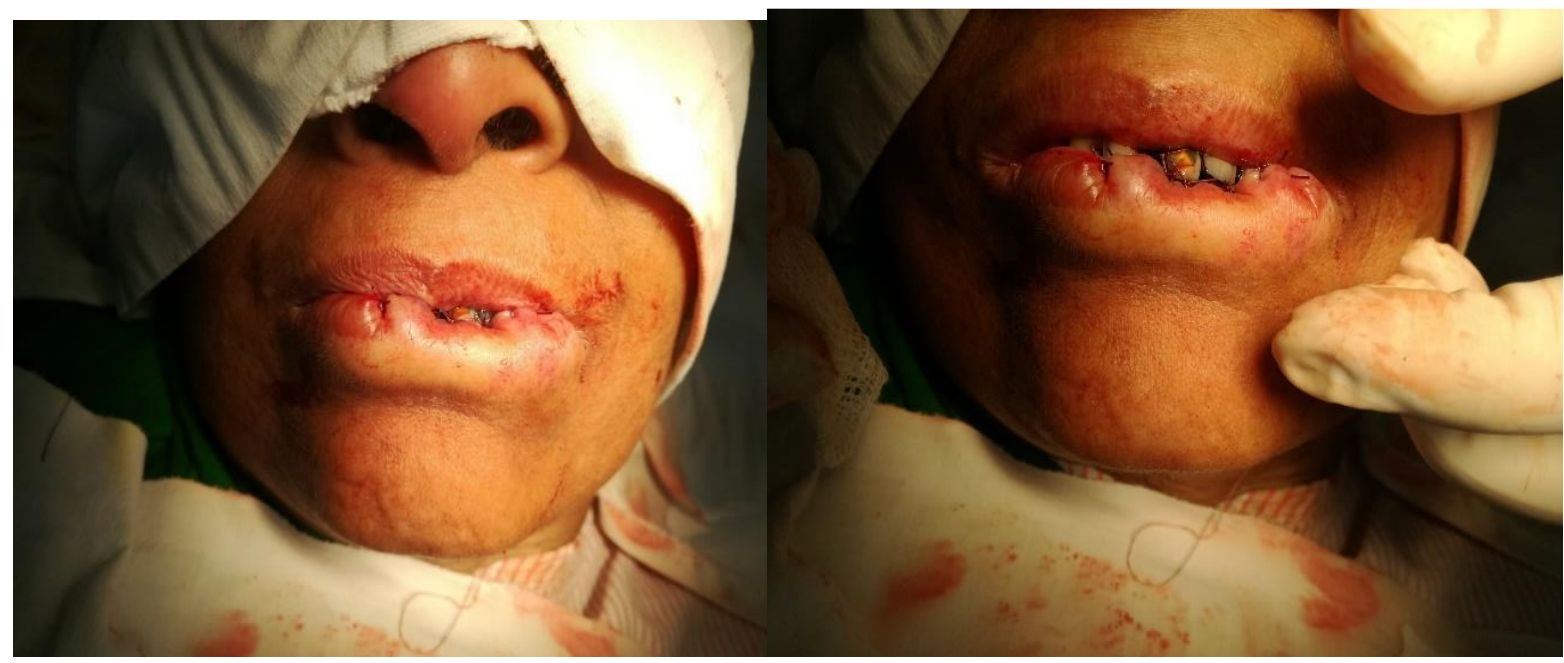

(o)

(p)

Fig 3:- (e-p) steps reconstruction 
ISSN No:-2456-2165

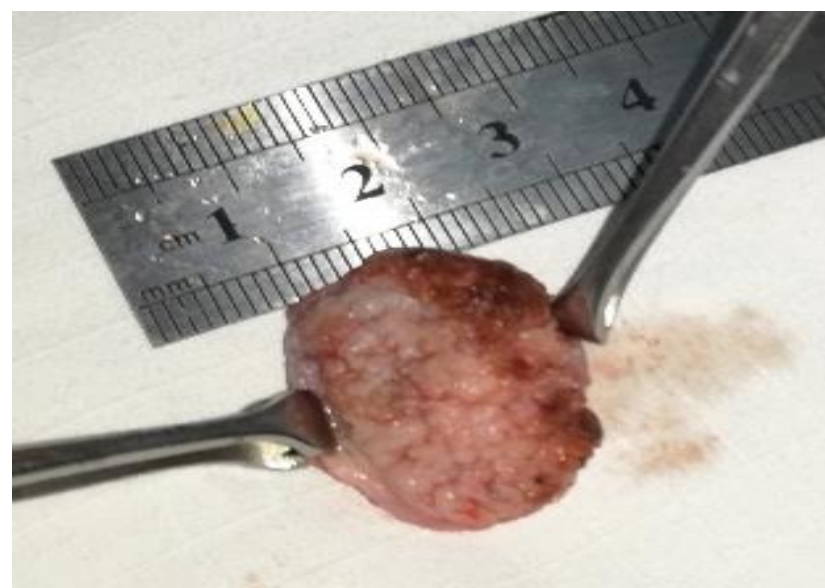

(j)

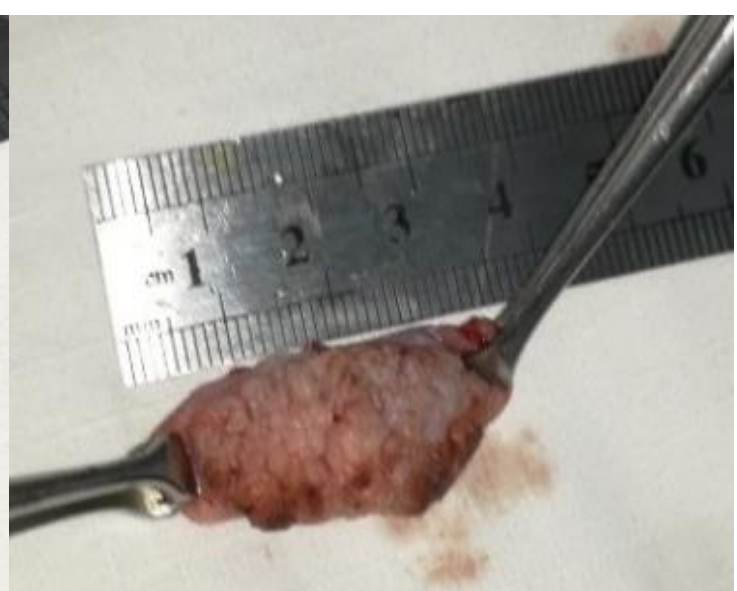

(k)

Fig 4:- (j-k) excised tissue

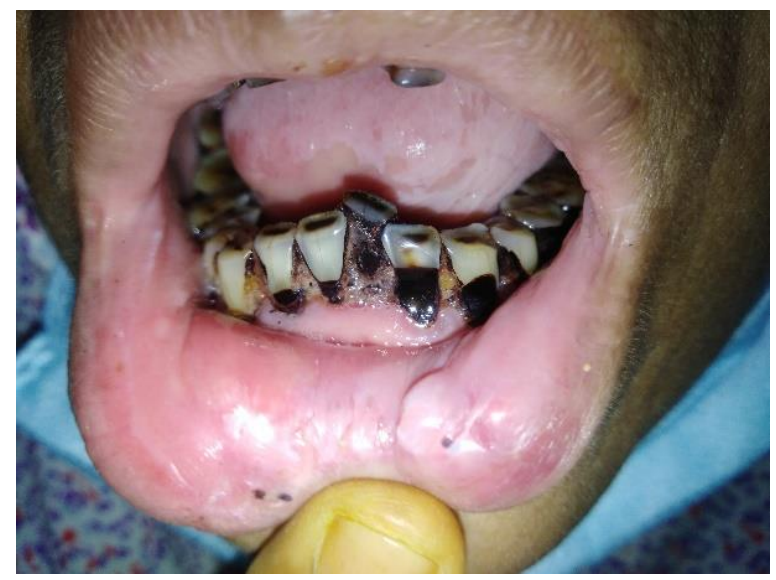

(q)

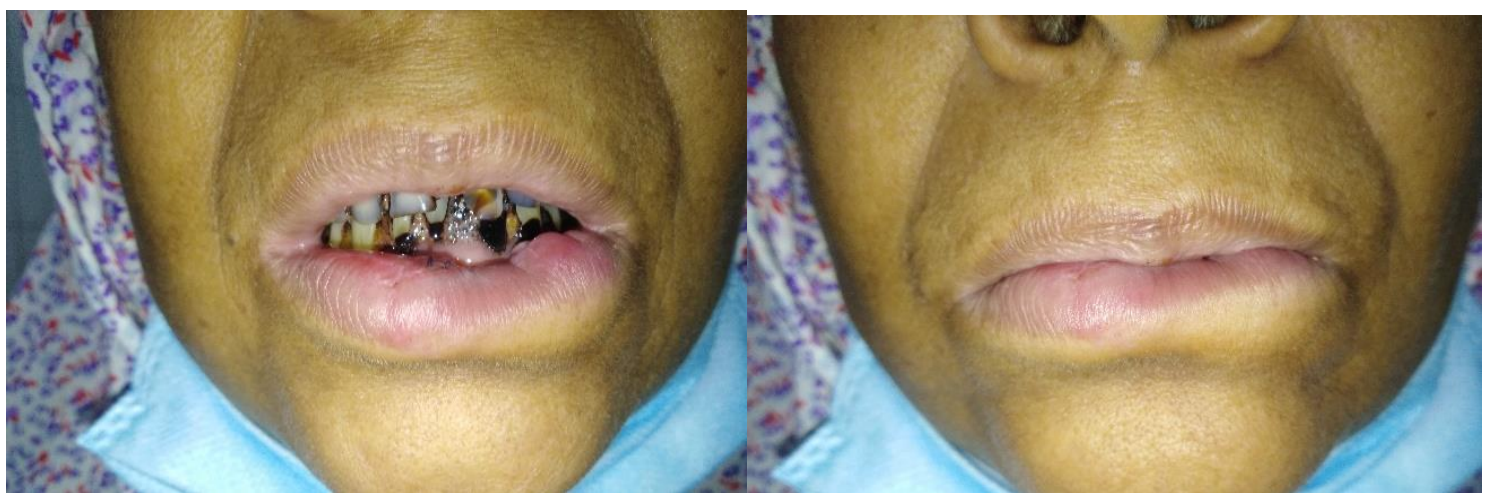

(r)

Fig 5:- (q-s) after 3 weeks postoperatively

Fine needle aspiration cytology (FNAC) was suggestive of chronic inflammatory lesion. Clinically it was a suspected case of SCC of lower lip. The incision line was infiltrated with $2 \%$ lidocaine with 1 in 200000 adrenaline solution. Planned excision with $6 \mathrm{~mm}$ healthy margin all around was done under local anesthesia with a slice of orbicularis oris muscle was done. After excision, the area became a rectangular shape which was $3.5 \mathrm{~cm} \times 2 \mathrm{~cm} \times 1.5$ $\mathrm{cm}$. the defect was reconstructed with a nearly $1.5 \mathrm{~cm} \times$ $1.5 \mathrm{~cm}$ advancement lip mucosa flap from the medial aspect and $0.5 \mathrm{~cm} \times 1.5 \mathrm{~cm}$ from the lateral aspect of the excision area. More than half of defect was covered with advancement flap. Outer (vermillion border) and inner incision line (gingival mucosa) was undermined to take some additional tissue. A portion of orbicularis oris muscle was raised and stitched in between outer vermillion border and inner gingival mucosa to fill the rest of the defect. The wound was closed in 2 layers with 3/0 vicryl suture without any significant tension. The patient was on oral cefuroxime for 10 days with antibiotic mouth wash for 5 days. She was allowed spoon feeding from the day of surgery. Stitches were removed on $5^{\text {th }}$ POD 
On subsequent follow up there was no gap in between the lips during closer of mouth. It was cosmetically well acceptable. The lesion was histopathologically confirmed as Invasive Squamous Cell Carcinoma grade-I. The margin was free of tumor. There was no vascular invasion.

\section{DISCUSSION}

Global estimates suggest increasing incidence of oral SCC. SCC constitutes $90 \%$ of oral malignant tumors. SCC is most common in lips after skin in the Head-Neck region. Among oral carcinoma, lip cancer is most common comprising nearly $35 \%$ of all. It is most likely due to sun exposure, although tobacco, alcohol, diet also plays role in the formation of Oral SCC. Majority of lip SCC arises in the vermillion border ${ }^{4}$.

Lip cancer can arise both from superficial layer or full thickness (including muscle, skin) of lip. Treatment varies according to the site and extension of the lesion. For a superficial lesion involving lower lip- vermillionectomy $y^{3,5}$ or "lip shave" 3,5 or "lip scalp" operation is an established treatment though most surgeons are accustomed to operate in full thickness for a superficial, medium to large sized lesion and to reconstruct the defect with different described flaps.

Lip shave is a simple procedure and can be done under local anesthesia. Aged patients with comorbidity can be the ideal group for local anesthesia in whom there is risk of General anesthetic drugs. Reconstruction with local lip mucosal advancement flap is easier. Gingivo-buccal mucosa can be undermined to take some additional tissue for reconstruction of local defect.

There are several flaps described in the literature for reconstruction of lower lip defect like Abbe lip switch flap, Estlander flap, Karapandzic Flap and all these $e^{6,7,8,9,10}$ is described to reconstruct full thickness lower lip defect with excellent outcome.

In the majority of cases, superficial defect of the lower lip best treated with full thickness wedge excision and primary closer in involve skin. up to one third of lip can be removed or excised by simple wedge excision and the defect can be closed primarily in layers. Though in elderly patients it is much easier due to the tissue laxity and it can be safely done under local anesthesia without any anatomical defect ${ }^{3}$.

\section{CONCLUSION}

Case selection is very important, as oncological outcome should have the ultimate priority rather reconstruction. One should have adequate case to case preoperative reconstruction planning. Whenever possible, reconstruction should be done with lip mucosa as it gives very good functional and aesthetic outcome.

\section{REFERENCES}

[1]. Neligan PC. Strategies in lip reconstruction. Clin Plast Surg. 2009 Jul. 36(3):477-85

[2]. Sushrata. An English Translation Of the Susrata Sambita. Based on original Sanskrit Text. Edited and Published by Kaviraj Kunja Lal Bhishagratna.

[3]. Omar A. Ahmed. Lip reconstruction.Oral cavity tumour including lip reconstruction. Scott-Browns Otolaryngology Head \& neck Surgery . Vol 3. Chapter 12,page; 190.

[4]. Düzgün S, Ünlü E, Pekdemir İ, Yilanci S, Ünlü RE. Management of Squamous Cell Carcinoma of The Lower Lip: Analysis of Five Years' Experience (78 Patients) and Review of The Literature KBBForum. 2013;12

[5]. All Answers. November 2018. Lower Lip Shave for Squamous Cell Carcinoma Reconstruction. [online]. Available, lower-lip-shave-squamous-cell-carcinoma8698.php?vref=1 [Accessed 18 August 2020].

[6]. Dieffenbach JF. Die operative chirurgie. Leipzig Brockhaus: 1845. Vol 1: 423.

[7]. Dieffenbach JF. Chirurgische Erfahrungen, bensonders uber die Wiederherstellung Zerstoerter Theile des Menschlichen Koerpers nach Neuen Methoden. Berlin: TCF Enslin; 1829. 34.

[8]. Sabattini P. Cenno storico dell-origine e progresso della rinoplastica e cheiloplastica seguito dalla descrizione di queste operazioni sopra un solo individuo. Bologna: Balla Arti; 1838.

[9]. Abbe R. A new plastic operation for the relief of deformity due to double harelip. Med Rec. 1898. 53:447.

[10]. Estlander JA. Methode d'autoplastie de la joue ou d'une levre par un lambeau emprunte a l'autre levre. Rev Mens Med Chir. 1877. 1:344.

[11]. Mazzola RF, Lupo G. Evolving concepts in lip reconstruction. Clin Plast Surg. 1984 Oct. 11(4):583617. [Medline].

[12]. Kurth, Lip Shave or vermilionectomy: indications and technique. British Journal of Plastic Surgery.1957 Jul;10(2):156-62 